Alexander Schwerdtfeger-Klaus

Das ältere Eutiner Stadtbuch

(1469-1564) 


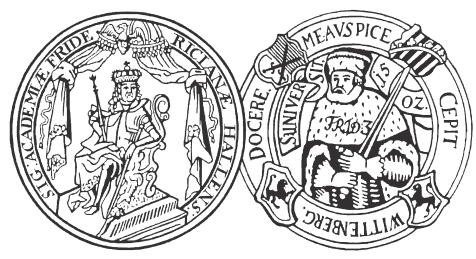

Hallische Beiträge zur Geschichte des Mittelalters und der Frühen Neuzeit Band 15

Herausgegeben von

Andreas Ranft und Andreas Pečar 


\section{Alexander Schwerdtfeger-Klaus}

\section{Das ältere Eutiner Stadtbuch (1469-1564)}

Quelle der administrativen Schriftlichkeit, der Sozialund Wirtschaftsgeschichte einer spätmittelalterlichen Kleinstadt

Edition und Forschungen 
Der Druck dieses Buches wurde mit Mitteln der Deutschen Forschungsgemeinschaft (DFG) gefördert.

ISBN 978-3-11-074722-5

e-ISBN (PDF) 978-3-11-075033-1

e-ISBN (EPUB) 978-3-11-075036-2

DOI https://doi.org/10.1515/9783110750331

\section{Library of Congress Control Number: 2021945842}

\section{Bibliografische Information der Deutschen Nationalbibliothek}

Die Deutsche Nationalbibliothek verzeichnet diese Publikation in der Deutschen

Nationalbibliografie; detaillierte bibliografische Daten sind im Internet über http://dnb.dnb.de abrufbar.

(C) 2022 Walter de Gruyter GmbH, Berlin/Boston

Satz: Meta Systems Publishing \& Printservices GmbH, Wustermark

Druck und Bindung: CPI books GmbH, Leck

www.degruyter.com 